\section{Nauplius}

The Journal OF The

Brazilian Crustacean Society

e-ISSN 2358-2936

www.scielo.br/nau www.crustacea.org.br

\title{
Coprophagy in detritivores: methodological design for feeding studies in terrestrial isopods (Crustacea, Isopoda, Oniscidea)
}

\author{
Pedro Henrique Pezzi ${ }^{1}$ (D) orcid.org/0000-0003-4324-5078 \\ Paula Beatriz Araujo ${ }^{1}$ (D) orcid.org/0000-0002-7587-3936 \\ Camila Timm Wood ${ }^{1}$ (D) orcid.org/0000-0002-6802-6229
}
1 Departamento de Zoologia (Laboratório de Carcinologia), Instituto de Biociências, Universidade Federal do Rio Grande do Sul, Porto Alegre, Rio Grande do Sul, Brazil
ZOOBANK: http://zoobank.org/urn:lsid:zoobank.org:pub:8CD08D97-80C3-4354- 9F3B-FD35FA7AD7B5

\begin{abstract}
Isopods consume feces in laboratory conditions. We investigated the effects of coprophagy on food consumption and assimilation and on isopod biomass to determine the best methodological design for feeding performance experiments. We used three species of isopods representing different ecomorphological groups and two leaves with different nitrogen content. We tested three treatments: (1) free access to feces; (2) periodic removal of feces and (3) net acting as a barrier to the feces. We did not find significant difference in any isopod or leaf species for consumption rate. Assimilation efficiency did not differ significantly for any isopod or leaf either. Only growth rate was significantly different, but only for the species Atlantoscia floridana (Van Name, 1940) with the leaf Machaerium stipitatum, and it may be due to the short duration of experiments and the isopods' susceptibility to environmental changes. Thus, we recommend the treatment access to study consumption and growth rates since it does not require any special material or extra time. If the focus is assimilation efficiency, we suggest the treatment removal because it provides more accurate values. Furthermore, more fragile species such as A.floridana require larger sample number and/ or longer experiment duration for more reliable data analyses.
\end{abstract}

\section{KEYWORDS}

CORRESPONDING AUTHOR

Assimilation efficiency, consumption rate, biomass change, growth rate, woodlice 


\section{INTRODUCTION}

Terrestrial isopods are soil detritivores involved in decomposition and nutrient cycling. Due to this functional role, several studies were dedicated to understand isopods' nutritional requirements (Zimmer, 2002) and contribution to soil processes (Jones et al., 2006). Studies related to their role in ecotoxicology (van Gestel et al., 2018), soil processes and ecosystem services (Quadros and Araujo, 2008; David, 2014) and effects of climate change on soil fauna (Hassall et al., 2018) frequently include feeding performance experiments. Microcosm approach is usually preferred in feeding experiments with woodlice. Although microcosm experiments minimize habitat complexities (van Gestel et al., 2018), certain behaviors, such as coprophagy can still influence feeding parameters.

Woodlice consume feces in laboratory conditions as well as in the wild (Szlávecz and Pobozny, 1995; Montesanto and Cividini, 2017). This behavior may be related to the need to fulfill the copper demand since it is an essential part of hemocyanin and they are unable to extract it from plant tissue (Wieser, 1966; Wieser, 1968; Zimmer, 2002). When animals are fed with a copper-free diet and coprophagy is prevented, copper content in the body drops because of the loss in the feces (Weißenburg and Zimmer, 2003), suggesting the importance of consuming feces. It may also be related to other nutrients that are not sufficiently ingested by litter consumption (Wieser, 1968) or as a source of microorganisms' enzymes that aid in the breakdown of recalcitrant compounds and also as the consumption of microorganisms as food source (Hassall and Rushton, 1982; Carefoot, 1984; Gunnarsson and Tunlid, 1986). These explanations are not mutually exclusive and we cannot explain the coprophagous behavior yet. As there are discussions related to the nutritional significance of this behavior to the animals (Zimmer, 2002), some feeding performance studies deal with this behavior by removing feces periodically from experimental units to avoid coprophagy interference.

The consumption of feces can be avoided by the use of nets that serve as a barrier so the animal cannot access the feces (Loureiro et al., 2006; Wood et al., 2012), or by manual removal every one or two days using tweezers (Wood and Zimmer, 2014). Both methods demand time and/or material and there is a question of comparability of studies that allow coprophagy with those that avoid the behavior. The effects of coprophagy vary with the physiology of the isopod species, with the leaves offered as food and with the developmental stage of the individuals (Zimmer, 2002); however, Szlavecz and Maiorana (1998) and Kautz et al. (2002) could not find clear evidence of nutritive benefits of the coprophagous behavior to Porcellio scaber Latreille, 1804 and, so far, it has not been established if coprophagy affects the feeding rates of terrestrial isopods. This raises the question of whether or not spending time removing the pellets manually or using nets to avoid coprophagy is worth it and/or even necessary in such experiments.

Thus, the aim of this article is to investigate if coprophagy influences feeding rates of terrestrial isopods using three different species. We investigated the effects on food consumption and food assimilation and on biomass change of isopods using higher and lower quality leaves (higher and lower quantity of nitrogen, respectively, sensu Zimmer, 2008), in order to suggest the best methodological design for studies related to feeding rates. We hypothesize that we would find: (1) no significant difference for consumption, but higher values in treatments where coprophagy is avoided; (2) no significant difference for assimilation, although with variation according to access to and maintenance of feces; and (3) no significant difference for biomass change.

\section{Material and Methods}

\section{Isopods and leaves species}

For the experiments, we used three terrestrial isopod species: (1) Atlantoscia floridana (Van Name, 1940) (Philosciidae) representing the ecomorphological group of runners, (2) Balloniscus glaber Araujo and Zardo, 1995 (Balloniscidae) representing the clinger group and (3) Armadillidium vulgare (Latreille, 1804) (Armadillidiidae) as a roller representative. We used species representing these ecomorphological groups (sensu Schmalfuss, 1984) because the runners, clingers and rollers constitute the largest part of the diversity of isopods. Moreover, these ecomorphological groups have different morphologies and life strategies that are correlated with their environment and behavior. The animals were collected at Morro Santana, Porto Alegre, Rio Grande do Sul (3004'11.3”S 5107'19.2”W). They 
were then transported to laboratory and maintained in culture chamber with ad libitum soil and leaves from the source site until the beginning of experiments. We only used intermolt animals and ovigerous females were excluded from the study since reproduction and molt are processes that are known to interfere in the consumption of food. The mean biomass was 0.0052 $\pm 0.0007 \mathrm{~g}$ for A. floridana, $0.0243 \pm 0.0012 \mathrm{~g}$ for $B$. glaber and $0.0735 \pm 0.0029 \mathrm{~g}$ for $A$. vulgare.

Leaf litter was also collected from the same locations of the animals and leaves of the two abundant species Lithraea brasiliensis Marchand (Anacardiaceae) (lower nitrogen content) and Machaerium stipitatum (DC.) Vogel (Fabaceae) (higher nitrogen content) (cf. Quadros et al., 2014) were sorted out, cut and kept in a freezer $\left(-5^{\circ} \mathrm{C}\right)$ until the start of the experiment. These leaves were selected based on their abundance and importance to isopods in the collection location (Quadros et al., 2014).
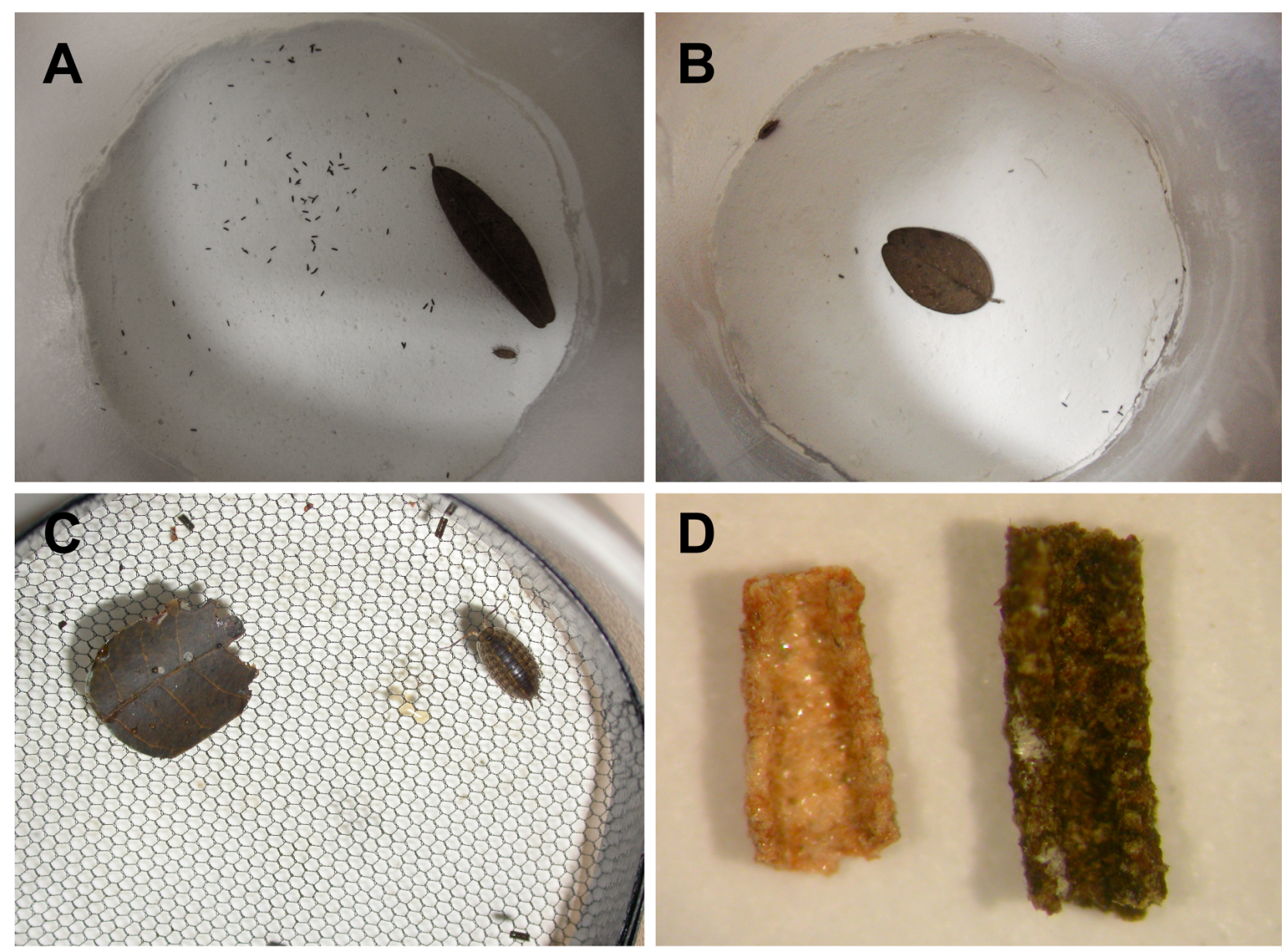

Figure 1. Experimental units for feeding rates tests with terrestrial isopods and fecal pellets from different food sources. A) Treatment access; coprophagy is allowed. B) Treatment removal; coprophagy and bacterial activity on feces are avoided. C) Treatment net; coprophagy is avoided and bacterial activity on feces allowed. D) Fecal pellet from carrot (left) and decomposing leaf (right) consumption.

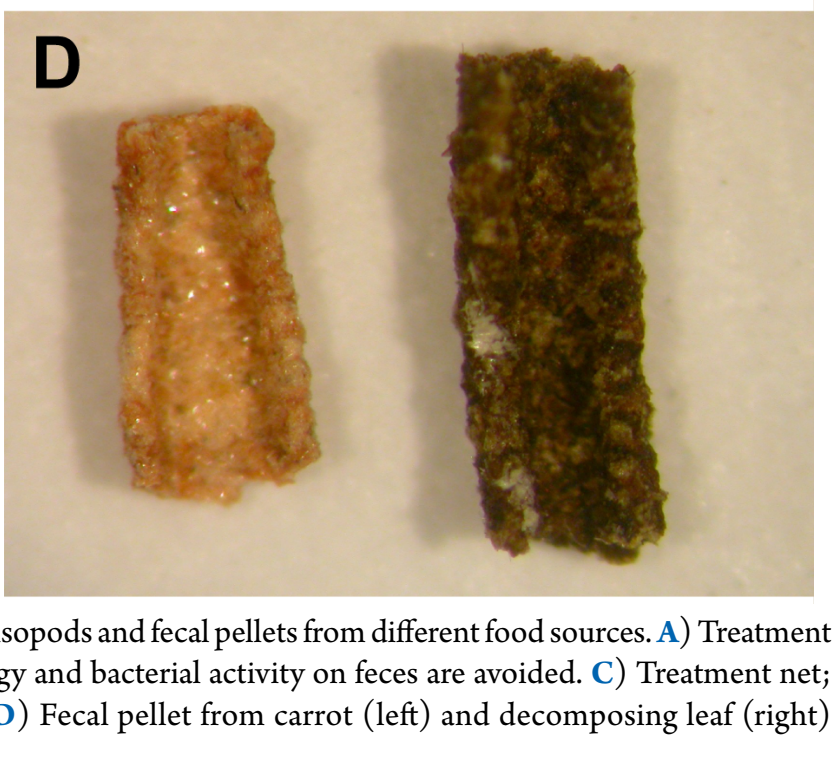

\section{Treatments and experimental unit setup}

We used three treatments for the experiments: 1) free access to the feces (access); 2) daily manual removal of the feces, kept frozen until the end of experiments (removal) and 3) net to avoid the access to the feces, kept in the experimental unit (net) (Fig. $1 \mathrm{~A}-\mathrm{C}$ ). A total of 15 units were used for each species/ leaf/treatment, totaling 270 units. Individuals that died or molted during the experiment were removed from the analyses. Before and after the experiments, the animals were fed with carrots so that the feces had a different coloration (Fig. 1D), so only the plant material consumed during the experiments were analyzed (Wood et al., 2012). The units contained one previously weighed animal and one food source type. The experiment lasted seven days and the units were monitored every one or two days. At the end of the experiments, the feces and food left were oven-dried at 
$60^{\circ} \mathrm{C}$ and $40^{\circ} \mathrm{C}$, respectively, for $48 \mathrm{~h}$. We maintained control units with only the food source for the same period of time in order to discount the leaf mass lost due to autogenic changes from feeding rates. For this, we maintained leaves in units with either plaster (access and removal treatments) or net over plaster (net treatment) substrates. We then calculated the mean biomass loss from the treatment and subtracted this percentage from the consumed value obtained in experimental units with animals.

\section{Rate calculations and data analyses}

We used linear regressions to estimate initial and final biomass of isopods in order to minimize water fluctuation interference. For this, animals were weighed every one or two days throughout the experiment and the linear regression equation of each animal was used for initial and final biomass calculation.

Consumption rate, assimilation efficiency and growth rate were calculated for each experimental unit as proposed by Waldbauer (1968) (Table 1) for the endpoints food consumption, food assimilation and isopod biomass change. Endpoints are presented as indexes but analyzed by Covariance Analysis
(ANCOVA) as proposed by Raubenheimer and Simpson, 1992 (Table 1). Food assimilation was not analyzed statistically for $A$. floridana due to interference of plaster consumption, which altered the mass of the feces and we considered assimilation of $100 \%$ when there was no feces in the units.

Pearson correlation was used to determine association between cumulative survivorship and time for each animal species. Analysis of Covariance was used to compare regressions among treatments within isopod species and among species. As there was no difference, we performed the analyses using units of both leaves in order to increase sample number (Table 1). All statistical analyses and normality tests were conducted using SPSS software 18. Treatments were compared for each animal species and food source.

\section{Results}

We did not find significant difference in the mean animal biomass of the animals for B. glaber and $A$. vulgare with any of the leaves and for $A$. floridana with M. stipitatum. The experiment with A. floridana and L. brasiliensis presented a significant difference in the

Table 1. Feeding performance endpoints with respective rate calculation (adapted from Waldbauer, 1968) and suggested statistical analyses (as proposed by Raubenheimer and Simpson, 1992) for experiments with soil invertebrates.

\begin{tabular}{|c|c|c|}
\hline Endpoint & Rate & Statistical analyses \\
\hline Food consumption & $\begin{array}{l}\text { Consumption Rate }(\mathrm{CR}) \\
\text { Equation: }\left[\left(\mathrm{m}_{\mathrm{if}}-\mathrm{m}_{\mathrm{af}}\right)-\mathrm{m}_{\mathrm{c}}\right] / \mathrm{m}_{\text {isop }}{ }^{*} \text { day } \\
\text { Unit: } \mathrm{mg} \text { food } / \mathrm{g} \text { isopod }{ }^{-{ }^{*} \mathrm{day}^{1}}\end{array}$ & $\begin{array}{l}\text { ANCOVA - Fixed factor: treatment } \\
\text { Dependent: consumed food } \\
\text { Covariates: duration; } \\
\text { initial isopod mass }\end{array}$ \\
\hline Food assimilation & $\begin{array}{l}\text { Assimilation Efficiency }(\mathrm{AE}) \\
\text { Equation: }\left(\mathrm{m}_{\mathrm{cf}}-\mathrm{m}_{\mathrm{p}}-\right)^{*} 100 / \mathrm{m}_{\mathrm{cf}} \\
\text { Unit: } \%\end{array}$ & $\begin{array}{l}\text { ANCOVA - Fixed factor: treatment } \\
\text { Dependent: pellets weight } \\
\text { Covariates: duration; consumed food; } \\
\quad \text { initial isopod mass }\end{array}$ \\
\hline Biomass change & $\begin{array}{l}\text { Growth Rate }(\mathrm{GR}) \\
\text { Equation: }\left(\mathrm{m}_{\text {isop }}-\mathrm{m}_{\text {isop }}\right) / \mathrm{t}^{*} \mathrm{~m}_{\text {isop }} \\
\text { Unit:g isopod } \text { day }^{-1}\end{array}$ & $\begin{array}{c}\text { ANCOVA - Fixed factor: treatment } \\
\text { Dependent: final isopod mass } \\
\text { Covariate: duration; initial isopod mass; consumed food. }\end{array}$ \\
\hline Biomass change (from 0) & - & $\begin{array}{l}\text { Paired t-test - Fixed factor: treatment } \\
\text { Variable 1: initial isopod mass } \\
\text { Variable 2: final isopod mass }\end{array}$ \\
\hline Survivorship & $\begin{array}{c}\text { Cumulative survivorship (\%) } \\
\text { through time (days) }\end{array}$ & $\begin{array}{l}\text { Linear regression - Dependent: survivorship } \\
\text { Independent: duration } \\
\text { ANCOVA - Factor: treatment } \\
\text { Dependent: survivorship } \\
\text { Independent: duration }\end{array}$ \\
\hline
\end{tabular}

$\mathrm{m}_{\mathrm{if}}=$ initial food mass $(\mathrm{mg} \mathrm{DW}) ; \mathrm{mf}_{\mathrm{ff}}=$ final food mass $(\mathrm{mg} \mathrm{DW}) ; \mathrm{m}_{\mathrm{c}}=$ percentage of lost mass in control leaves; $\mathrm{m}_{\text {isop }}=\mathrm{mean}$ isopod mass ( $\mathrm{g}$ FW); $\mathrm{A}=$ assimilation; $\mathrm{m}_{\mathrm{cf}}=$ mass of consumed food $(\mathrm{mg} \mathrm{DW}) ; \mathrm{m}_{\mathrm{p}}=$ pellet feces mass $(\mathrm{mg} \mathrm{DW})$, , where: GR = growth rate; $\mathrm{m}_{\text {isopf }}=$ final isopod mass $(\mathrm{g} \mathrm{FW}) ; \mathrm{m}_{\text {isopi }}=$ initial isopod mass $(\mathrm{g} \mathrm{FW}) ; \mathrm{t}=$ time $($ days $) ; \mathrm{m}_{\text {isop }}=$ mean isopod mass $(\mathrm{g} F W)$. DW $=$ dry weight; $\mathrm{FW}=$ fresh weight. 
mean animal biomass in treatment net. Animals were bigger in this treatment because small animals would go through the net.

Food consumption (Fig. 2) did not differ significantly for any of the animal species and for any of the leaves (Table 1). However, the consumption of L. brasiliensis was higher in all of the treatments for all isopod species.

Food assimilation ranged from 11.3 to $64.4 \%$ for A. floridana, 24.9 to $51.6 \%$ for B. glaber and 16.7 to $39.6 \%$ for A. vulgare (Fig. 3). Food assimilation was not analyzed for A. floridana with the leaf M. stipitatum due to the low sample size available. The mass of the feces was altered due to consumption of plaster and also because plaster got stuck on the fecal pellets. No significant difference was detected for A.floridana with L. brasiliensis. We did not find significant difference for assimilation in B. glaber and A. vulgare for any of the plant species (Table 1).

Biomass change was very close to zero for all isopod species (Fig 4). A. floridana presented the highest variations (Fig. 4A); however, the only difference was in the species A. floridana with the leaf M. stipitatum between access and net treatments (Table 2). In this case, we also performed an analysis of variance for growth rate itself and still found significant difference, although at a lower degree of significance $(p=0.015$ whereas ANCOVA provided a $\mathrm{p}=0.004)$. We also performed a paired t-test to verify if there was a

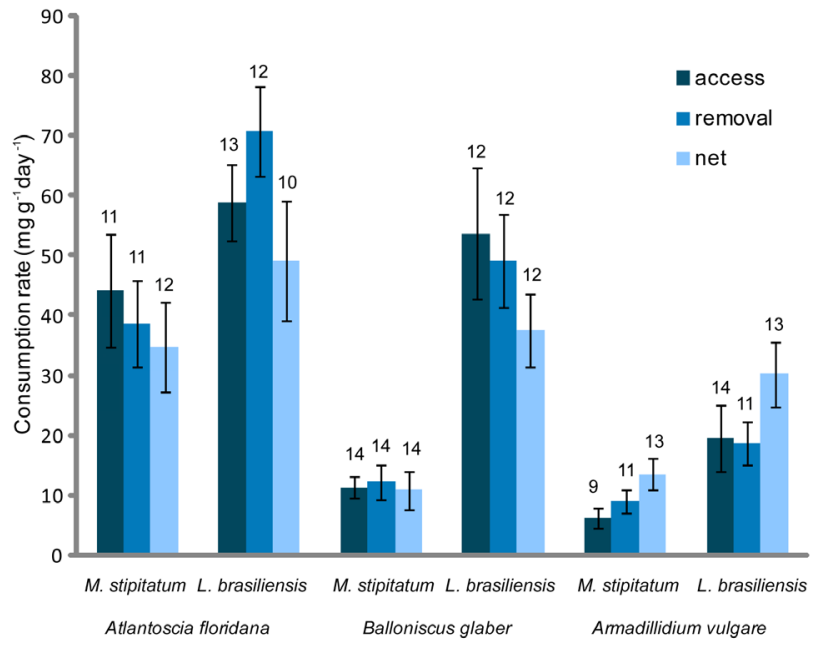

Figure 2. Consumption rates of three different isopod species with two different food sources in three different treatments (access, removal and net). The values are mean \pm SE and the numbers on top indicate the sample for each index significant difference between initial and final biomass, i.e., if the biomass change was significantly different from zero. There was a significant difference for the treatment net $(\mathrm{t}=-7.08 ; \mathrm{df}=11 ; \mathrm{p}=0.002)$, but no difference for treatments access $(t=0.67 ; \mathrm{df}=10$; $\mathrm{p}=0.519)$ or removal $(\mathrm{t}=-2.18 ; \mathrm{df}=10 ; \mathrm{p}=0.054)$. It is important to note that the average initial mass of A. floridana on the treatment net was higher than in the other treatments. We did not find significant difference on growth among treatments for B. glaber nor $A$. vulgare, and values were very low and close to zero (Fig. 4B).

We found association between cumulative survivorship and time for each treatment of each isopod species (considering both leaves together) (Table 3). Survivorship was not significantly different among treatments within the same isopod species (A. floridana: $\mathrm{F}_{2,32}=2.28 ; \mathrm{p}=0.118 ;$ B. glaber: $\mathrm{F}_{2,32}=0.22$; $\mathrm{p}=0.805 ;$ A. vulgare: $\left.\mathrm{F}_{2,32}=1.36 ; \mathrm{p}=0.270\right)$. However, when considering all treatments together, survivorship was significantly different among isopod species $\left(\mathrm{F}_{2,104}\right.$ $=3.53 ; \mathrm{p}=0.033)$, with difference between B. glaber (highest) and $A$. floridana (lowest) $(\mathrm{p}=0.011)$.

\section{Discussion}

Our results suggest that coprophagy does not affect food consumption significantly since no difference was observed in any of the leaves tested

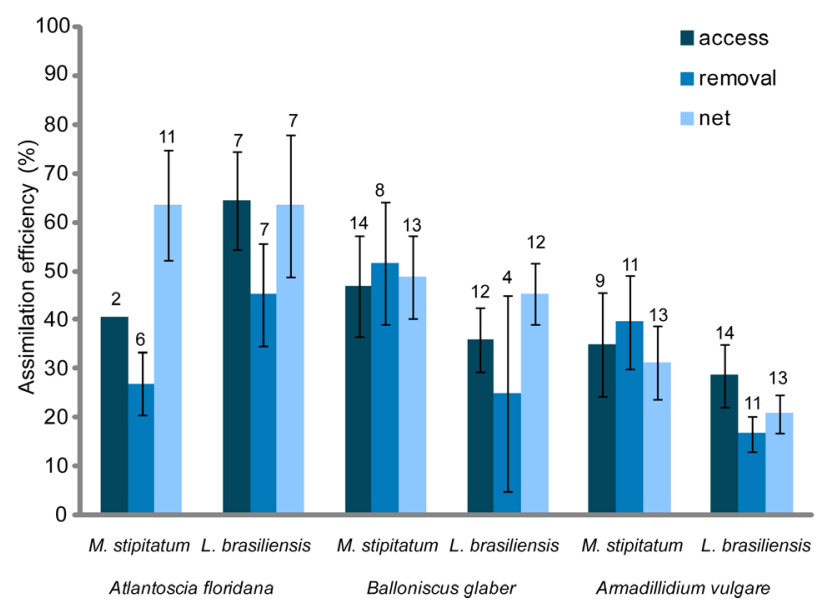

Figure 3. Assimilation efficiency of isopods fed on two different leaves in treatments access, removal and net. The values are mean $\pm \mathrm{SE}$ and the numbers on top indicate the sample number for each index 
A

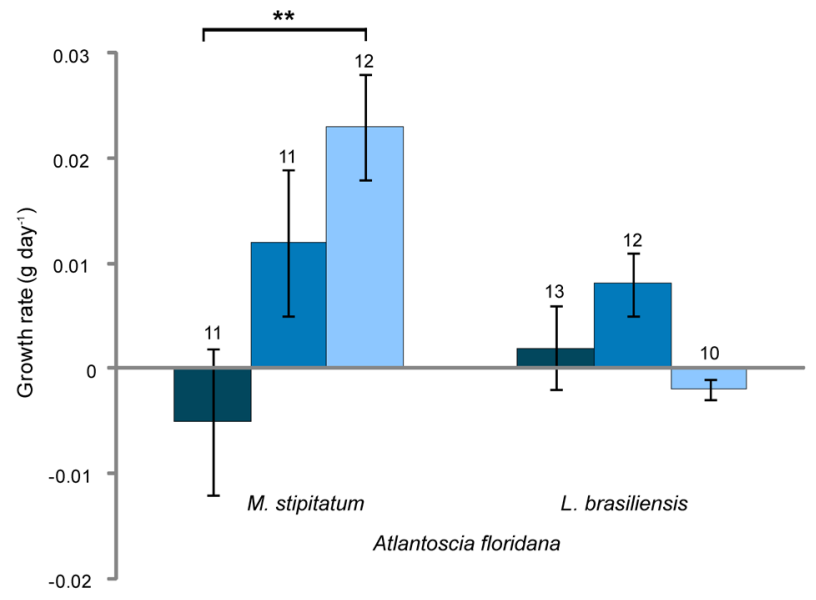

B

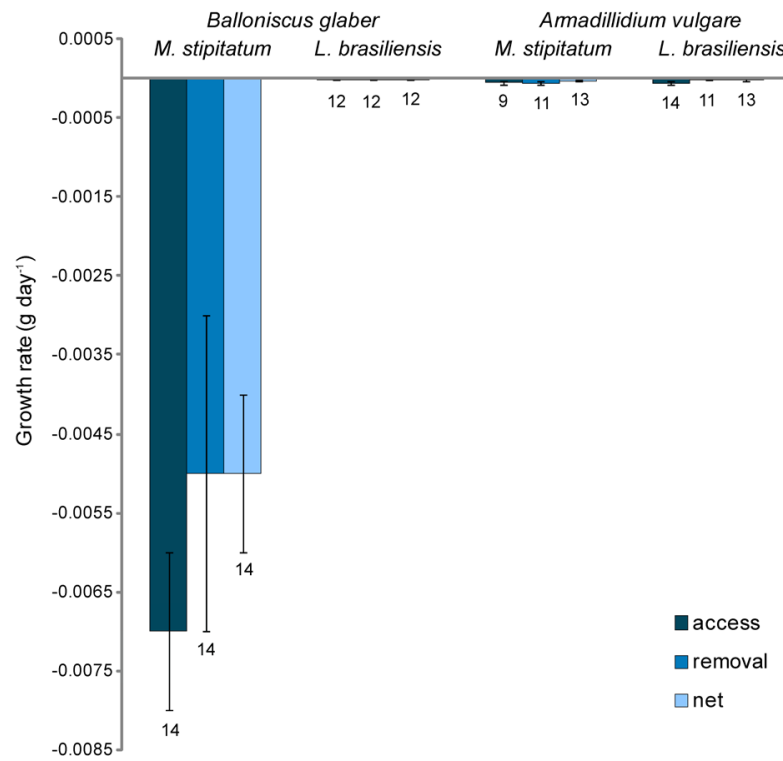

Figure 4. Growth rate of isopods in three different treatments. A. Growth rate of Atlantoscia floridana. B. Growth rate of Balloniscus glaber and Armadillidium vulgare. The values are mean \pm SE and the numbers on top indicate the sample number for each index.

Table 2. Analysis of covariance for feeding parameters of Atlantoscia floridana, Balloniscus glaber and Armadillidium vulgare fed on Machaerium stipitatum and Lithraea brasiliensis.

\begin{tabular}{|c|c|c|c|c|}
\hline Isopod species & Food source & Food consumption & Food assimilation & Biomass change \\
\hline \multirow[t]{2}{*}{$\begin{array}{l}\text { Atlantoscia floridana } \\
\text { (runner) }\end{array}$} & M. stipitatum & $\begin{array}{c}\mathrm{F}_{2,32}=0.499 \\
\mathrm{p}=0.612\end{array}$ & - & $\begin{array}{c}\mathrm{F}_{2,32}=6.736 \\
\mathrm{p}=0.004\end{array}$ \\
\hline & L. brasiliensis & $\begin{array}{c}\mathrm{F}_{2,31}=1.304 \\
\mathrm{p}=0.286\end{array}$ & $\begin{array}{c}\mathrm{F}_{2,16}=0.034 \\
\mathrm{p}=0.966\end{array}$ & $\begin{array}{c}\mathrm{F}_{2,31}=1.355 \\
\mathrm{p}=0.273\end{array}$ \\
\hline \multirow[t]{2}{*}{$\begin{array}{l}\text { Balloniscus glaber } \\
\text { (clinger) }\end{array}$} & M. stipitatum & $\begin{array}{c}\mathrm{F}_{2,38}=0.089 \\
\mathrm{p}=0.915\end{array}$ & $\begin{array}{c}\mathrm{F}_{2,30}=1.350 \\
\mathrm{p}=0.275\end{array}$ & $\begin{array}{c}\mathrm{F}_{2,38}=0.833 \\
\mathrm{p}=0.442\end{array}$ \\
\hline & L. brasiliensis & $\begin{array}{c}\mathrm{F}_{2,32}=1.343 \\
\mathrm{p}=0.275\end{array}$ & $\begin{array}{c}\mathrm{F}_{2,23}=2.607 \\
\mathrm{p}=0.095\end{array}$ & $\begin{array}{c}\mathrm{F}_{2,32}=0.705 \\
\mathrm{p}=0.502\end{array}$ \\
\hline \multirow[t]{2}{*}{$\begin{array}{l}\text { Armadillidium vulgare } \\
\text { (roller) }\end{array}$} & M. stipitatum & $\begin{array}{c}\mathrm{F}_{2,29}=2.907 \\
\mathrm{p}=0.071\end{array}$ & $\begin{array}{c}\mathrm{F}_{2,28}=0.170 \\
\mathrm{p}=0.844\end{array}$ & $\begin{array}{c}\mathrm{F}_{2,28}=1.550 \\
\mathrm{p}=0.230\end{array}$ \\
\hline & L. brasiliensis & $\begin{array}{c}\mathrm{F}_{2,34}=1.594 \\
\mathrm{p}=0.218\end{array}$ & $\begin{array}{c}\mathrm{F}_{2,33}=0.583 \\
\mathrm{p}=0.564\end{array}$ & $\begin{array}{c}\mathrm{F}_{2,33}=1.813 \\
\mathrm{p}=0.179\end{array}$ \\
\hline
\end{tabular}

Table 3. Pearson correlation of cumulative survivorship and time of three isopod species in feeding experiments with treatments access, removal and net.

\begin{tabular}{lcccc}
\hline Isopod species & Treatment & $\mathrm{F}$ & $\mathrm{p}$ & $\mathrm{R}$ \\
\hline $\begin{array}{l}\text { Atlantoscia floridana } \\
\text { (runner) }\end{array}$ & Access & $\mathrm{F}_{1,11}=32.30$ & $<0.001$ & 0.87 \\
& Removal & $\mathrm{F}_{1,1}=14.54$ & 0.003 & 0.77 \\
& Net & $\mathrm{F}_{1,11}=57.93$ & $<0.001$ & 0.92 \\
$\begin{array}{l}\text { Balloniscus glaber } \\
\text { (clinger) }\end{array}$ & Access & $\mathrm{F}_{1,11}=12.71$ & 0.005 & 0.75 \\
& Removal & $\mathrm{F}_{1,11}=15.70$ & 0.003 & 0.78 \\
& Net & $\mathrm{F}_{1,11}=19.05$ & 0.001 & 0.81 \\
$\begin{array}{l}\text { Armadillidium vulgare } \\
\text { (roller) }\end{array}$ & Access & $\mathrm{F}_{1,11}=6.08$ & 0.033 & 0.61 \\
& Removal & $\mathrm{F}_{1,11}=20.53$ & 0.001 & 0.82 \\
& Net & $\mathrm{F}_{1,11}=97,53$ & $<0.001$ & 0.95 \\
\hline
\end{tabular}


for any isopod. Hence, studies that avoid and studies that allow coprophagy are comparable. Moreover, the consumption of the lower nitrogen content leaf L. brasiliensis was higher for all three isopod species analyzed. This possibly happened because the animal needs to consume more food to meet the nutrient demand from low quality leaves. This was similar to food preference results found by Quadros et al. (2014) that isopods prefer L. brasiliensis over M. stipitatum. They suggest this difference may be related to terpenes and alkaloids present in $M$. stipitatum that could be offsetting the high nitrogen content.

Food assimilation varied greatly among isopod species, leaf type and also among treatments. One explanation is the low sample number in some treatments due to consumption of plaster, which altered the mass of the feces and/or plaster glued to the fecal pellets. It happened for A. floridana and B. glaber species and the units where this happened were not included in the analyses. Assimilation did not show statistical difference for A. vulgare in any of the leaves tested, suggesting that any of the treatments can be used.

However, in projects where the main concern is to verify food assimilation, we suggest the treatment removal. This treatment shows more accurate values of assimilation because it minimizes both coprophagy and bacterial activity. Even though the treatment net also prevents coprophagy, there are two problems with this approach: (1) it does not prevent bacterial activity on feces and (2) animals may go through the net and get trapped in the bottom of the unit depending on their body size. If the animals are trapped in the bottom, the feces will then be the only available food source, possibly increasing coprophagy while preventing leaf consumption.

Regarding biomass change, our results suggest that any treatment can be used. We found significant difference for A. floridana with $M$. stipitatum but not for L. brasiliensis leaf or any of the other two isopod species. This difference could be related to the short duration of the experiments, which hinders statistical analysis of growth. Atlantoscia floridana has a thinner and more delicate cuticle (Wood et al., 2017) and their populations are more susceptible to environmental changes (Quadros and Araujo, 2007) and water fluctuation. Thus, longer experiments should be performed in order to elucidate the effects of coprophagy on growth rate but taking in consideration the intermolt length of the studied species in order to prevent influence from ecdysis.

\section{Conclusions}

Based on our findings, we propose the following:

1) For consumption and growth rate, any treatment can be used. Therefore, we suggest the treatment access to feces because this method does not require any special material and/or time and implies less stress/ interference to the animal.

2) For assimilation efficiency, any treatment is effective. However, treatment removal of feces shows more accurate values of assimilation efficiency, being indicated for studies with this purpose focus.

$3)$ For smaller animals such as A.floridana $(\sim 1 \mathrm{~mm}$ of cephalothorax width, cf. Araujo and Bond-Buckup, 2004), we suggest avoiding treatment net because animals can get stuck in the bottom of the unit if they go through the net. This will prevent the animals from consuming the leaf and possibly increase coprophagy. Mesh size can not be smaller because the pellets still must fall to the bottom of the unit.

4) Animals more susceptible to environmental fluctuations such as A. floridana demand a larger sample size or longer experiment duration.

5) Plaster is important to maintain humidity in the units. Treatment net can be an alternative to prevent larger animals consuming plaster, since they are not on the plaster surface.

6) Feeding carrots to the animals prior and after experiments is a good way to sort out fecal pellets from the prior food source and the food source being studied. When isopods consume carrots, the feces have an orange coloration that is easily distinguishable.

7) Linear regression is an appropriate approach to remove the influence of water quantity in the animal biomass. Thus, the animals should be weighed every two or three days throughout the experiment.

8) Analysis of Covariance (ANCOVA) is the more appropriate form to statistically analyze feeding rates because it is more accurate than Analysis of Variance (ANOVA). For growth rate in A. floridana with $M$. stipitatum, we found $\mathrm{p}=0.004$, whereas we found one significance degree higher than in ANOVA $(p=0.015)$. 


\section{ACKNOWLEDGMENTS}

The authors wish to thank Conselho Nacional de Desenvolvimento Científico e Tecnológico (CNPq) for granting scholarship to PHP and fellowship to PBA and Coordenação de Aperfeiçoamento de Pessoal de Nível Superior (CAPES) for granting a scholarship to CTW. We are also grateful to Instituto de Biociências of UFRGS for giving financial assistance to perform the experiments. This paper resulted from PHP's final project and we would like to thank Tainã G. Loureiro, Diego C. Kenne and the two anonymous reviewers for contributions on an earlier version of this manuscript.

\section{References}

Araujo, P.B. and Bond-Buckup, G. 2004. Growth curve of Atlantoscia floridana (van Name) (Crustacea, Isopoda, Philosciidae) from a Brazilian restinga forest. Revista brasileira de Zoologia, 21: 1-8.

Carefoot, T.H. 1984. Studies on the nutrition of the supralittoral isopod Ligia pallasii using chemically defined artificial diets: assessment of vitamin, carbohydrate, fatty acid, cholesterol and mineral requirements. Comparative Biochemistry and Physiology Part A: Physiology, 79: 655-665.

David, J.F. 2014. The role of litter-feeding macroarthropods in decomposition processes: a reappraisal of common views. Soil Biology and Biochemistry, 76: 109-118.

Gunnarsson, T. and Tunlid, A. 1986. Recycling of fecal pellets in isopods: microorganisms and nitrogen compounds as potential food for Oniscus asellus L. Soil Biology and Biochemistry, 18: 595-600.

Hassall, M.; Moss, A.; Dixie, B. and Gilroy, J.J. 2018. Interspecific variation in responses to microclimate by terrestrial isopods: implications in relation to climate change. Zookeys, 801: 5-24.

Hassall, M. and Rushton, S.P. 1982. The role of coprophagy in the feeding strategies of terrestrial isopods. Oecologia, 53: 347-381.

Jones, C.G.; Gutiérrez, J.L.; Groffman, P.M. and Shachak, M. 2006. Linking ecosystem engineers to soil processes: a framework using the Jenny State Factor Equation. European Journal of Soil Biology, 42: 39-53.

Kautz, G.; Zimmer, M. and Topp, W. 2002. Does Porcellio scaber (Isopoda: Oniscidea) gain from coprophagy? Soil Biology and Biochemistry, 34: 1253-1259.

Loureiro, S.; Sampaio, A.; Brandão, A.; Nogueira, A.J. and Soares, A.M. 2006. Feeding behaviour of the terrestrial isopod Porcellionides pruinosus Brandt, 1833 (Crustacea, Isopoda) in response to changes in food quality and contamination. Science of the Total Environment, 369: 119-128.
Montesanto, G. and Cividini, S. 2017. A crossover design to assess feeding preferences in terrestrial isopods: a case study in a Mediterranean species. Biologia, 72: 194-203.

Quadros, A.F. and Araujo, P.B. 2007. Ecological traits of two neotropical oniscideans (Crustacea, Isopoda). Acta Zoologica Sinica, 53: 241-249.

Quadros, A.F. and Araujo, P.B. 2008. An assemblage of terrestrial isopods (Crustacea) in southern Brazil and its contribution to leaf litter processing. Revista brasileira de Zoologia, 25: 58-66.

Quadros, A.F.; Zimmer, M.; Araujo, P.B. and Kray, J.G. 2014. Litter traits and palatability to detritivores: a case study across bio-geographical boundaries. Nauplius, 22: 103-111.

Raubenheimer, D. and Simpson, S.L. 1992. Analysis of covariance: an alternative to nutritional indices. Entomologia experimentalis et applicata, 62: 221-231.

Schmalfuss, H. 1984. Eco-morphological strategies in terrestrial isopods. Symposia of the Zoological Society of London, 53: 339-368.

Szlavecz, K. and Maiorana, V.C. 1998. Supplementary food in the diet of the terrestrial isopod Porcellio scaber Latr. (Isopoda: Oniscidea). Israel Journal of Zoology, 44: 413-421.

Szlávecz, K. and Pobozny, M. 1995. Coprophagy in isopods and diplopods: a case for indirect interaction. Acta Zoologica Fennica, 196: 124-128.

van Gestel, C.A.M; Loureiro, S. and Idar, P. 2018. Terrestrial isopods as model organisms in soil ecotoxicology: a review. ZooKeys, 801: 127-162.

Waldbauer, G.P. 1968. The consumption and utilization of food by insects. Advances in Insect Physiology, 5: 229-288.

Weißenburg, M. and Zimmer, M. 2003. Balancing nutritional requirements for copper in the common woodlouse, Porcellio scaber (Isopoda: Oniscidea). Applied soil ecology, 23: 1-11.

Wieser, W. 1966. Copper and the role of isopods in degradation of organic matter. Science, 153: 67-69.

Wieser, W. 1968. Aspects of nutrition and the metabolism of copper in isopods. American Zoologist, 8: 495-506.

Wood, C.T.; Araujo, P.B. and Štrus, J. 2017. Morphology, microhabitat selection and life-history traits of two sympatric woodlice (Crustacea: Isopoda: Oniscidea): a comparative analysis. Zoologischer Anzeiger, 268: 1-10.

Wood, C.T.; Schlindwein, C.C.D.; Soares, G.L.G. and Araujo, P.B. 2012. Feeding rates of Balloniscus sellowii (Crustacea, Isopoda, Oniscidea): the effects of leaf litter decomposition and its relation to the phenolic and flavonoid content. ZooKeys, 176: 231-245.

Wood, C.T. and Zimmer, M. 2014. Can terrestrial isopods (Isopoda: Oniscidea) make use of biodegradable plastics? Applied Soil Ecology, 77: 72-79.

Zimmer, M. 2002. Nutrition in terrestrial isopods (Isopoda: Oniscidea): an evolutionary-ecological approach. Biological Reviews of the Cambridge Philosophical Society, 77: 455-493.

Zimmer, M. 2008. Detritus. p. 903-911. In: S.V. Jørgensen and B.D. Fath (eds), General ecology, Volume 2, Encyclopedia of ecology. Oxford, UK, Elsevier. 